$\widehat{\text { Review Article }}$

\title{
SCOPE IN MINIMALIST SYNTAX
}

\author{
NORIAKI YUSA \\ Miyagi Gakuin Women's College*
}

Syntax of Scope, by Joseph Aoun and Yen-hui Audrey Li, The MIT Press, Cambridge, Massachusetts, 1993, ix +225pp.

\section{Introduction}

Since the seminal work of May (1977), the operation called quantifier raising (QR) has generally been assumed to account for quantifier scope represented at Logical Form (LF). This book (henceforth SS), dealing with similarities and differences between Chinese and English, is one of the most comprehensive studies of relative operator scope ever written within the Pre-Minimalist framework. The status of QR applying at LF is crucial in a theory which assumes D-Structure, SStructure, Phonetic Form (PF) and LF as significant linguistic levels, since arguments for the existence of LF come from the difference between principles that hold at S-Structure and those which hold at LF. For example, consider the relevant examples from Chomsky (1981: 196-197):

(1) a. Which book that John read did he like?

b. ${ }^{*}$ He liked every book that John read.

On the assumption that the Binding Theory applies at S-Structure and

* I am indebted to two anonymous $E L$ reviewers for valuable comments that have materially improved this paper. This indebtedness should not be construed as implying agreement on their part with the claims made herein. I also wish to thank Chris Huston for suggesting some stylistic improvements. After submitting this review article, I had access to Hornstein (1995), which deals with quantification in Minimalism, but unfortunately I have not incorporated his ideas into the system here because of the lack of time, though two proposals are similar in relevant respects. This study is supported in part by a Grant-in-Aid for Scientific Research from the Japanese Ministry of Education, Grant No. 06610441.

English Linguistics 12 (1995) 319-346 - 319 -

(C) 1995 by the English Linguistic Society of Japan 
QR adjoins quantified phrases (QPs) to IP at LF, (1a) and (1b) have the same LFs in relevant respects:

(2) a. for which book $x$ that John read, he liked $x$

b. for every book $x$ that John read, he liked $x$

At S-Structure, he does not c-command John in (1a), but it does in (1b). At LF, the pronoun does not c-command its antecedent in (2a) or (2b). Thus, the difference between (1a) and (1b) can be captured at S-Structure, but not at LF.

However, the Minimalist framework outlined by Chomsky (1991, 1993, 1994) derives all conditions on derivations and representations from "bare output conditions", that is, from conditions imposed on the interfaces of the grammatical component with other cognitive components. In effect, a syntactic representation consists only of the external interface levels, PF and LF. With the elimination of DStructure and S-Structure as linguistic levels, the question of whether LF exists as a level distinct from S-Structure has become meaningless, and so has the issue as to whether quantifier scope is best represented at S-Structure or at LF. LF is the only level equipped with grammatical information relevant to interpretation. In the Pre-Minimalist framework, S-Structure is presupposed and those who argue for the existence for LF bear the burden of proof. ${ }^{1}$ However, in the Minimalist Program it is those who deny LF and argue for S-Structure that have the obligation for proving their claim.

One of the leading ideas behind the Minimalist Program is that "the basic principles of language are formulated in terms of notions drawn from the domain of (virtual) conceptual necessity" (Chomsky (1993: $5)$ ). The analyses offered in $S S$, reviewed from this perspective, crucially rely on the notions and principles which have been abandoned or derived from more fundamental ones in the Minimalist Program. This is where I take issue, and in what follows I will try to recast some of the Pre-Minimalist analyses offered in $S S$ in terms of Minimalist assumptions, proposing alternatives which better cohere with the Minimalist paradigm.

1 Chomsky (1981: 343) writes: The most fundamental level of representation is SStructure. Surface structure is relevant to phonology, but to syntax except insofar as it has implications concerning S-Structure. The arguments in favor of particular conclusions about S-Structure are generally far stronger than arguments bearing on D-Structure and LF, as we have seen throughout. 
Chapters 1 and 2 of $S S$ are devoted respectively to developing the theory of the relative scope of two QPs in Chinese and English and the interaction between QPs and Wh-phrases. In Chapter 3 Aoun and $\mathrm{Li}$ (henceforth $A \& L$ ) give a unified analysis of the phenomena dealt with in the previous chapters. Chapters 4 and 5, in turn, provide an account of the interactions between operators within simplex NPs and complex NPs. Chapter 6 discusses the interaction between QPs and adjunct Wh-phrases. Finally, Chapter 7 touches on the syntax of scope in Japanese, which exhibits behavior different from Chinese or English.

This review article is organized as follows. Section 1 introduces the basic facts and principles that underlie A\&L's analyses of scope, referring to some specific analyses offered, and section 2 deals with the elimination of NP-traces in scope determination. I will go through in some detail the analyses found in $S S$; for Chapters 1 and 2 roughly correspond to A\&L (1989) and A\&L (1991), respectively, but the analyses are radically modified in the following chapters. It will be helpful first of all to consolidate the arguments that motivate these modifications. With respect to the modifications, I will focus my attention on intermediate traces in section 3, and show in section 4 that A\&L's approach to island effects on quantification is insufficient on theoretical and empirical grounds. Section 5 will cover wh-movement in the Minimalist framework, into which I will incorporate the analysis of quantifier scope in section 6 . In section 7 I will discuss what place QR fits into in the Minimalist framework. Some concluding remarks will be made in section 8 .

\section{Basic Facts and Principles}

In this section I first recapitulate some basic facts and principles that will be the starting point for later discussions, and then I focus on the specific analyses offered by A\&L. ${ }^{2}$ The generalization which A\&L seek to capture is summarized in (3), with the relevant examples shown in (4) to (8):

(3) a. Active sentences are ambiguous in English (4) but similar ambiguity does not arise in Chinese (5).

2 All of the examples I will use from section 1 to section 3 are from SS. 
b. In Chinese, active sentences (5) do not exhibit ambiguity, though passive sentences (6), like English active sentences, do show such ambiguity.

c. There is a subject-object asymmetry in scope interaction between QPs and Wh-phrases (7)-(8) in English and Chinese.

(4) a. Everyone loves a woman. (everyone $=$ a woman $)^{3}$

b. A woman loves everyone. (a woman $=$ everyone)

(5) Meigeren dou xihuan yige nuren. (meigeren $>$ yige nuren) every all like one woman

'Everyone loves a woman.'

(6) Meigeren dou bei yige nuren zhuazoule.

everyone all by one woman arrested

(meigeren $=$ yige nuren $)$

'Everyone was arrested by a woman.'

(7) a. Who bought everything (for Max)? (who > everything)

b. Shei (gei Zhangsan) maile meige dongxi?

(shei $>$ meige dongxi)

who (for Zhangsan) bought every thing 'Who bought everything (for Zhangsan)?'

(8) a. What did everyone buy (for Max)? (what = everyone)

b. Meigeren dou (gei Zhangsan) maile shenme?

(shenme $=$ meigeren $)$

everyone all (for Zhangsan) bought what

'What did everyone buy (for Zhangsan)?'

In order to account for the facts in (4)-(6), A\&L propose that quantifier scope is determined by the interaction of the Minimal Binding Requirement (MBR) and the Scope Principle (SP):

(9) MBR: Variables must be bound by the most local potential A-binder.

(10) SP: A quantifier A may have scope over a quantifier B iff A c-commands a member of the chain containing $B$.

(11) The Potential $\bar{A}$-binder: A qualifies as a potential $\bar{A}$-binder for $\mathrm{B}$ iff $\mathrm{A}$ c-commands $\mathrm{B}, \mathrm{A}$ is in an $\mathrm{A}$-position, and the

3 The following notations for scope interpretation will be used in this paper:

(i) $\mathrm{A}>\mathrm{B}$ iff $\mathrm{A}$ has scope over $\mathrm{B}$.

(ii) $\mathrm{A}=\mathrm{B}$ iff $\mathrm{A}$ and $\mathrm{B}$ are ambiguous with respect to scope. 
assignment of the index of A to $B$ would not violate Principle $\mathrm{C}$ of the binding theory.

A\&L revise the SP later in $S S$ in order to give a unified account of the relative scope of QPs and the interaction between QPs and $W h$ phrases, but (9) and (10) suffice for the introduction of A\&L's claim concerning scope determination. The MBR prohibits the crossing quantifiers (12a) and nested quantifiers (12b), while allowing (12c):
a. ${ }^{*} \mathrm{QP}_{1} \ldots \mathrm{QP}_{2} \ldots \mathrm{x}_{1} \ldots \mathrm{x}_{2} \ldots$
b. ${ }^{*} \mathrm{QP}_{2} \ldots \mathrm{QP}_{1} \ldots \mathrm{x}_{1} \ldots \mathrm{x}_{2} \ldots$
c. $\mathrm{QP}_{1} \ldots \mathrm{x}_{1} \ldots \mathrm{QP}_{2} \ldots \mathrm{x}_{2} \ldots$

Given the MBR and the SP, VP-Internal Subject Hypothesis is essential for the success of $S S$. If we assume that at LF, QPs adjoin to VP and IP, then the simplified LF representation of (4a) is (13), where $t_{i}$ indicates a subject NP trace in VP:

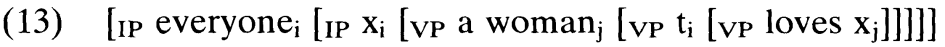
It should be noted here that NP traces are not subject to the MBR. In (13), everyone c-commands $a$ woman, yielding the reading where the former has scope over the latter. In turn, $a$ woman c-commands $t_{i}$, the $\mathrm{NP}$ trace of everyone, yielding the wide scope reading of a woman. Therefore, (4a) is ambiguous. A pressing question then is why the Chinese sentence in (5) is unambiguous. A\&L interpret the difference in scope ambiguity as being due to the difference in constituent structures between Chinese and English, contra Huang (1982), who stipulates that c-command relations at S-Structure are isomorphic to ones at LF in Chinese but not in English. This stipulation is, however, unwarranted both empirically and theoretically. Given the fact that LF-operations are "invisible," it is unlikely that LF varies from language to language. According to the Barriers framework, on which A\&L build their theory, V-to-I raising is required to deprive VP of its barrierhood. But due to a defective system of verbal inflection, Chinese lacks the subject raising and therefore a VP internal subject trace responsible for the wide scope reading of the object in (13). ${ }^{4}$ The Chinese active sentence in (5) has the LF representation shown in (14):

${ }^{4}$ To be fair with A\&L, the explanation here is from A\&L (1989). They still assume in $S S$ that there is no subject trace in VP, but do not say how a subject is generated. Judging from the representation given in $S S$, they seem to assume that it is base-generated in SPEC IP. 
(14) [IP meigeren $_{i}\left[{ }_{1 P} x_{i}\right.$ [VP yige nuren $n_{j}$ [VP xihuan $x_{j}$ ]]]] In this configuration, meigeren has scope over yige nuren. It should be clear from the contrast between (13) and (14) that the existence of a subject NP-trace in VP produces scope ambiguity. A\&L's analysis and Huang's analysis make the same predictions about almost all active sentences, but the former is more attractive than the latter insofar as it reduces the differences in scope between English and Chinese to visible (inflectional) properties and makes unnecessary the dubious stipulation mentioned above.

A\&L observe that the plausibility of their analysis is enhanced by considering the problem noted in (3b), which poses a challenge to Huang (1982). The isomorphic effect just mentioned above cannot be observed in Chinese passive sentences such as (6), where meigeren ccommands yige nuren but not vice versa. Huang's analysis predicts that only the wide scope interpretation of meigeren should be possible, which is contrary to the empirical evidence. With the VP-internal trace in mind, consider the LF representation of (6):

(15) [IP Meigeren $n_{i}\left[\right.$ IP $x_{i}$ [vP yige nuren $n_{j}\left[v P\right.$ dou bei $x_{j}$ zhuazoule $\left.\left.\left.\left.\mathrm{t}_{\mathrm{i}}\right]\right]\right]\right]$

It can easily be observed that in addition to the fact that meigeren c-commands yige nuren, the latter c-commands the NP-trace $t_{\mathrm{i}}$. Accordingly, scope ambiguity in (6) is explained by using the same rationale as found in the explanation of ambiguity in English active sentences such as (4). Thus, A\&L's approach is descriptively and theoretically superior to Huang's approach. One of the most appealing features of $S S$ 's approach to scope ambiguity is its straightforward account of the sharp asymmetries observed in $(1 \mathrm{a}-\mathrm{b})$ by making effective use of VP-internal subject traces. However, extending the analysis to the scope interaction of QPs and Wh-phrases leads A\&L to the conclusion that NP traces are not relevant in determining scope.

With this caveat concerning the VP-internal subject trace, let us look at the LF representation of $(8 \mathrm{a})$ :

(16) [CP what $_{j}$ [IP everyone ${ }_{i}$ [IP $x_{i}$ [VP1 $t_{i}\left[V P 2\right.$ buy $\left.\left.\left.\left.\left.x_{j}\right]\right]\right]\right]\right]$

Note that in violation of the prohibition of the stacking of two QPs in $(12 \mathrm{a}, \mathrm{b})$, the $w h$-phrase and the QP are stacked in (16). The difference comes from the definition of the potential $\bar{A}$-binder written in the language of the Generalized Binding Condition: the assignment of the index of everyone to the variable $x_{\mathrm{j}}$ would violate Principle $\mathrm{C}$ since this variable would be bound by $t_{\mathrm{i}}$ or $x_{\mathrm{i}}$. As a result, everyone is not the 
potential $\overline{\mathrm{A}}$-binder for $x_{\mathrm{j}}$ and what serves as the most local $\overline{\mathrm{A}}$-binder, respecting the MBR. The SP predicts that (8a) should be ambiguous. (16) shows that what c-commands everyone and its variable, explaining the reading where what has scope over everyone. In turn, everyone has the variable $x_{\mathrm{j}}$ bound by what in its c-command domain, yielding the interpretation where everyone takes scope over what. Note here that in this account the variable plays a role though the NP-trace does not play any role.

However, consider the following two LFs of (7a) involving the adjunction of everything to $\mathrm{VP}_{1}$ or $\mathrm{VP}_{2}$ :

(17) a. $\left[w^{\prime} o_{i}\left[x_{i}\left[V_{P} 1 t_{i}\left[v P 2\right.\right.\right.\right.$ everything $\left.\left.\left.\left.{ }_{j}\left[V P 2 ~ V ~ x_{j}\right]\right]\right]\right]\right]$

b. $\left[w_{i} o_{i}\left[x_{i}\left[V P 1\right.\right.\right.$ everything $\left.\left.\left.{ }_{j}\left[V_{P} 1 t_{i}\left[V P 2 \quad V x_{j}\right]\right]\right]\right]\right]$

(17a) represents the reading with who taking scope over everything. This is to be expected under A\&L's analysis because the former ccommands the latter. However, an incorrect interpretation is to be predicted in the LF representation of (17b) under the assumption that NP-traces play a crucial role in the determination of scope. Everything c-commands the VP-internal trace $t_{\mathrm{i}}$, in addition to who c-commanding everything. The analysis predicts that (7a) should be ambiguous, but it is not the case. The conclusion that A\&L embrace is that NP-traces play no role whatever in scope determination, which is at odds with the conclusion they reached in the case of (4)-(6). ${ }^{5}$ The next section will be devoted to spelling out their revised analysis of scope without any reference to NP-traces.

\section{NP-Traces and QR}

SS differs from A\&L $(1989,1991)$ in that it eliminates the reference to NP-traces in scope determination. In order to do so, they propose two types of QR: NP-adjunction and Q(uantifier)-adjunction. The first adjoins the whole QP and the second adjoins only the bare Q. The crux of their proposal, following Barriers' assumptions, is the prohibition on adjunction to phrases in $\theta$-marked positions. QPraising is obligatory if the QP is in a $\theta$-position but optional otherwise.

5 A\&L's proposal amounts to parametrizing the VP-Internal Subject Hypothesis, but see Huang (1993) for VP-internal subject effects in Chinese. 
A\&L (p. 79) derive this assumption from the Theta Theory: "Since quantificational phrases, like other operators, are not referential expressions, these elements cannot remain in a $\theta$-position at LF; otherwise, the $\theta$-Criterion would be violated." On this assumption, typological differences between English and Chinese should be the result of the theta-status of subjects, assuming that objects are in $\theta$ positions in both languages. If we adhere to the assumption that SPEC IP is in a $\bar{\theta}$-position in English active sentences and Chinese passive sentences and that it is in a $\theta$-position in Chinese active sentences, it is possible to give a unified account of the observational generalization in (3). First, consider active sentences in English. The subject is in a $\bar{\theta}$-position, so the NP-adjunction of the subject is optional, while the NP-adjunction of the object is obligatory. From the S-Structure of (18), QR yields the following licit representations with the irrelevant details disregarded (In what follows, VP-internal traces are not included in view of the assumption that they are irrelevant to scope assignment):

(18) [IP someone [vP loves everyone]] (S-structure)

(19) a. [IP someone $\mathrm{m}_{\mathrm{m}}\left[\mathrm{IP} \mathrm{x}_{\mathrm{m}}\right.$ [vP everyone $\mathrm{v}_{\mathrm{n}}$ [vP loves $\left.\left.\left.\left.\mathrm{x}_{\mathrm{n}}\right]\right]\right]\right]$ (NP-adjunction of both someone and everyone)

b. [IP [NP some $_{i}\left[\mathrm{NP}_{\mathrm{i}}\right.$ one $\left.]\right]_{\mathrm{m}}\left[\mathrm{IP} \mathrm{X}_{\mathrm{m}}\left[\mathrm{VP}\left[\mathrm{NP}\right.\right.\right.$ every ${ }_{\mathrm{j}}\left[\mathrm{NP}_{\mathrm{j}} \mathrm{X}_{\mathrm{j}}\right.$ one $]]_{n}\left[\right.$ vp loves $\left.\left.\left.\left.x_{n}\right]\right]\right]\right]$ (Q-adjunction)

(20) a. [IP everyone ${ }_{n}\left[\right.$ IP someone [VP loves $\left.\left.x_{n}\right]\right]$ (NP-adjunction of the object only)

b. [IP [NP every $_{\mathrm{j}}\left[\mathrm{NP} \mathrm{X}_{\mathrm{j}}\right.$ one $\left.]\right]_{\mathrm{n}}\left[\mathrm{IP}\left[\mathrm{NP}\right.\right.$ some $_{\mathrm{i}}\left[\mathrm{NP} \mathrm{X}_{\mathrm{i}}\right.$ one $\left.]\right][\mathrm{VP}$ loves $\left.\left.x_{n}\right]\right]$ (Q-adjunction)

In order to account for scope ambiguity in terms of the proposed $\mathrm{QR}$, A\&L (p. 205, fn. 9) revise the SP as (21):

(21) The (revised) SP: An operator A may have scope over an operator $\mathrm{B}$ iff $\mathrm{A}$ or the minimal $\bar{\theta}$-phrase immediately dominating the operator and its restriction c-commands $\mathrm{B}$ or an $\bar{A}$-element coindexed with $\mathrm{B}$.

In (19b) the minimal $\bar{\theta}$-phrase immediately dominating some and its restriction one c-commands every. This is taken as the interpretation of some having scope over every. The opposite c-command relations hold in (20b), which represents the wide scope of every. It is important to note that in this analysis the adjoined $\mathrm{Q}$ does not ccommand anything outside the QP it is adjoined to. If c-command were defined in terms of exclusion, (20b) would violate the MBR since 
some $_{\mathrm{i}}$ would be the closest $\overline{\mathrm{A}}$-binder for $x_{\mathrm{n}}{ }^{6}$. However, scope is determined not by the c-command relation of Qs but by that of the QPs to which Qs are adjoined, as (19b) and (20b) show. Unfortunately, this discrepancy in the function of c-command with respect to the MBR and scope determination, while correctly describing the facts, strips $S S$ of its theoretical simplicity.

The strongest motivation for not restricting QR to Q-adjunction but including NP-adjunction as well is found in the evidence concerned with the antecedent-contained deletion (ACD), which A\&L claim shows that QR raises the whole QP. ${ }^{7}$ This is in fact the only argument there is in $S S$ for the claim that LF operation involves pied-piping and that $\mathrm{QR}$ can raise the whole NP as well. However, the QR approach to ACDs is not compatible with the Minimalist framework, where the LF movement of pied-piped phrases is avoided (Chomsky 1993: 25). Hornstein (1994) presents a solution to ACDs in terms of Amovement to SPEC AGRoP at LF. If this solution is tenable, there is no need for QR to include NP-adjunction.

6 The definition of c-command, which is essential to the analyses in $S S$, is defined as in (i):

(i) Node A c(onstituent)-commands node B iff the branching node $\alpha_{1}$ most immediately dominating $\mathrm{A}$ either dominates $\mathrm{B}$ or is immediately dominated by a node $\alpha_{2}$ that dominates $\mathrm{B}$, and $\alpha_{2}$ is of the same category type as $\alpha_{1}$ (p. 201, fn. 8).

However, in an approach that assumes that domination and c-command are defined as in (ii) and (iii), some $e_{\mathrm{i}}$ c-commands $x_{\mathrm{n}}$ in (20b):

(ii) $\alpha$ is dominated by $\beta$ only if it is dominated by every segment of $\beta$ (Chomsky (1986: 7).

(iii) $\quad \alpha$ c-commands $\beta$ iff $\alpha$ does not dominate $\beta$ and every $\gamma$ that dominates $\alpha$ dominates $\beta$ (ibid.: 8).

7 ACD sentences such as (i) show that a null VP cannot be reconstructed at SStructure:

(i) Dulles suspected everyone who Angleton did.

If the reconstruction involved a copy of the antecedent at S-Structure, an infinite regress would emerge, as shown in an infinite representation (ii):

(ii) Dulles [vp suspected everyone who Angleton [vp suspected everyone who Angleton [vp suspected everyone who Angleton ...]]]

May (1985) argues that this regress can be avoided by first QRing the whole quantifier phrase as in (iii) and then copying the antecedent VP as in (iv):

(iii) [IP [everyone who Angleton did] [IP Dulles [vP suspected $\left.\left.x_{\mathrm{i}}\right]\right]$ ]

(iv) [IP [everyone who Angleton suspected $\left.x_{\mathrm{i}}\right]_{\mathrm{i}}$ [IP Dulles [vP suspected $\left.\left.\left.x_{\mathrm{i}}\right]\right]\right]$ It is important to note that this explanation hinges crucially on the pied-piping of the whole QP at LF. 
Let us turn now to (18), which shows that the wide scope reading of the object over the subject is available in the case where NP-adjunction applies only to the object. This story also accounts in a unified way for the lack of scope ambiguity in Chinese active sentences, where the subject is in a $\theta$-position. As a result, the NP-adjunction must apply to the subject, yielding the representation which is approximately equivalent to (19b). This is why the subject always has scope over the object in Chinese active sentences. The same analysis handles the ambiguity in Chinese passive sentences, where the subject is in a $\bar{\theta}$ position like the subject in English active sentences. This permits the $\mathrm{NP}$-adjunction of the subject to be optional, resulting in the LF representations similar to (19b) and (20b) in relevant respects. This is interpreted as scope ambiguity in Chinese passive sentences. Under this approach, it is the optionality of NP-adjunction that is responsible for scope ambiguity. Notice here that the analysis does not refer to the VP-internal subject NP-trace at all, but depends in a crucial way on the availability of QP-adjunction: QP-adjunction cannot be dispensed with in an approach that ascribes differences in quantifier scope to the theta-statuses of subjects and objects, since these grammatical relations are properties of NPs, not Ns.

\section{Intermediate Traces and QR}

A\&L eliminate reference to NP traces and go on to eliminate reference to variables in A-positions in assigning the relative scope of Wh-phrases and QPs. The paradigm example showing that variables play a role in scope determination is illustrated by (8a), whose LF is given in (16). These data are, however, not hard and fast, and there is evidence suggesting that variables are not at work in the interaction of QPs and Wh-phrases. Consider the contrast between (22a) and (22b):

(22) a. ?What do you wonder whether everyone bought?

b. What do you think everyone bought?

(what $>$ everyone)

$($ what $=$ everyone $)$

Weak islands block the wide scope reading of the universal quantifier in (22a), as opposed to (22b), which enjoys scope ambiguity. (23a) and (23b) are the LF representations of (22a) and (22b), respectively:

(23) a. [what ${ }_{j}$ do [IP you wonder [CP whether [IP everyone ${ }_{i}$ [IP 


\section{$\mathrm{x}_{\mathrm{i}}$ [vP bought $\left.\left.\left.\left.\left.\left.\mathrm{x}_{\mathrm{j}}\right]\right]\right]\right]\right]\right]$

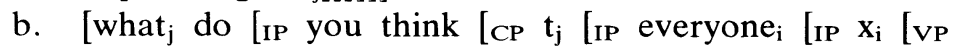 bought $\left.\left.\left.\left.\left.\left.\mathrm{x}_{\mathrm{j}}\right]\right]\right]\right]\right]\right]$}

Scope ambiguity is to be expected in (22b), since in (23b) everyone ccommands $x_{\mathrm{j}}$ and what c-commands everyone. However, the same ccommand relationships predict the same ambiguity in (22a), but this prediction is false: the universal QP cannot take scope over what. The difference between (22a) and (22b) lies in the presence of a weak island. A\&L conclude that variables do not play a role in scope determination, and instead focus on the role of intermediate traces in VP-adjoined positions. Consider the LF representations of (22a) and (22b) with the VP-adjunction of the Wh-phrase included:

(24) a. *[what ${ }_{j}$ do [IP you wonder [CP whether [IP everyone ${ }_{i}$ [IP $\mathrm{x}_{\mathrm{i}}\left[\mathrm{vP} \underline{\underline{x}}_{\mathrm{j}}\right.$ [vP bought $\left.\left.\left.\left.\left.\left.\left.\mathrm{x}_{\mathrm{j}}\right]\right]\right]\right]\right]\right]\right]$

b. [what ${ }_{j}$ do [IP you think [CP $t_{j}$ [IP everyone ${ }_{i}\left[_{I P} x_{i}\left[v P \underline{\underline{x}}_{j}\right.\right.$ [vP bought $\mathrm{x}_{\mathrm{j}}$ ]]]]]]]

In order to distinguish (24a) from (24b), A\&L invoke the ECP, such as the one formulated in Lasnik and Saito (1984)/Chomsky (1986), according to which $\underline{\underline{x}}_{j}$ is not antecedent-governed in (24a) but it is in (24b). They assume that $\underline{\underline{x}}_{j}$ has to be deleted in (24a), which makes it impossible for everyone $e_{i}$ to take scope over any member of the chain headed by what $^{8}$ In (24b), however, each intermediate trace is properly bound, obeying the ECP. In this representation what ccommands everyone and the latter c-commands the intermediate trace $\underline{\underline{x}}_{j}$, accounting for the ambiguity in (23b). A\&L's decision to invoke the ECP amounts to saying that only the $\overline{\mathrm{A}}$-members of an $\overline{\mathrm{A}}$-chain are relevant to scope assignment. They also give an additional corroborating example for the claim that intermediate traces play a role in scope determination:

(25) a. what didn't everyone buy? (what $>$ everyone)

b. *[CP what $_{j}$ [didn't [IP everyone ${ }_{i}\left[\begin{array}{ll}\text { IP } & x_{i}\end{array}\left[\begin{array}{ll}\mathrm{VP} & \underline{x}_{j}\end{array}\right]\right.$ VP buy $\left.\left.\left.\left.\left.\left.\mathrm{x}_{\mathrm{j}}\right]\right]\right]\right]\right]\right]$

The intermediate trace $\underline{\underline{x}}_{j}$ adjoined to VP is not antecedent-governed by what because the negation intervenes between what and $\underline{x}_{j}$. Thus, the intermediate trace is deleted, so that the universal QP cannot c-

8 It is not clear how to delete the intermediate trace under the Generalized Binding Condition, which they use in the definition of the Potential $\overline{\mathrm{A}}$-binder. 
command any $\overline{\mathrm{A}}$-member of the chain headed by what. A\&L take this as indicating the narrow scope of everyone.

Let us look at the examples in (7) and (8), which are accounted for on the assumption that variables are involved in scope determination. Consider first (7a), which is repeated in (26a) for convenience. Its LF representation is given in (26b):

(26) a. Who bought everything?

(who > everything)

b. [CP who $_{i}\left[I_{P} \mathrm{x}_{\mathrm{i}}\right.$ [VP everything ${ }_{\mathrm{j}}\left[\mathrm{VP}\right.$ buy $\left.\left.\left.\left.\mathrm{x}_{\mathrm{j}}\right]\right]\right]\right]$

In this configuration, the wide scope of who is evident. Consider (8a), represented in $(27 a)$ :

(27) a. what did everyone buy?

$($ what $=$ everyone $)$

b. [CP what ${ }_{j}$ did [IP everyone ${ }_{i}\left[I P X_{i}\left[\mathrm{VP} \underline{\underline{x}}_{j}\left[\mathrm{VP}\right.\right.\right.$ buy $\left.\left.\left.\left.\left.\mathrm{x}_{\mathrm{j}}\right]\right]\right]\right]\right]$

In the LF represented in (27b), what c-commands everyone and the latter c-commands the intermediate trace $\underline{\underline{x}}_{\mathrm{j}}$. Thus, (27a) is ambiguous. The picture of scope determination that A\&L have arrived at is as follows: only operators and intermediate traces are involved in computing scope. Therefore, the success of $S S$ crucially relies on the validity of intermediate traces in mental computation of scope interactions. In the next section, we will see that there is some evidence against A\&L's conclusion.

\section{Intermediate Traces in VP-Adjoined Positions}

$S S$ is theoretically superior to the earlier A\&L $(1989,1991)$ in that it eliminates the unnatural role of NP-traces, but the very fact that A\&L refer to VP-adjoined traces in the explanation of $W h / Q$ interactions opens a Pandora's box. I will argue below that A\&L's crucial assumption that intermediate traces are relevant to scope determination is supported on neither theoretical nor empirical grounds. Consider once again (24a) and (25b):

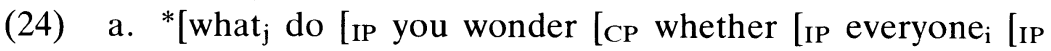
$\mathrm{x}_{\mathrm{i}}\left[\mathrm{vP} \underline{\underline{x}}_{\mathrm{j}}\left[\mathrm{vP}\right.\right.$ bought $\left.\left.\left.\left.\left.\left.\left.\mathrm{x}_{\mathrm{j}}\right]\right]\right]\right]\right]\right]\right]$

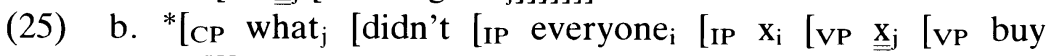
$\left.\left.\left.\left.\left.\mathrm{x}_{\mathrm{j}}\right]\right]\right]\right]\right]$ ]

A\&L assume that $\underline{\underline{x}}_{\mathrm{j}}$ in VP-adjoined positions is not present at LF. If whether acts as the first $\overline{\mathrm{A}}$-binder in (24a) and negation acts as the first $\overline{\mathrm{A}}$-binder in $(25 \mathrm{~b})$, both representations should violate the MBR, since $x_{\mathrm{j}}$ in the object position is not bound by the first $\overline{\mathrm{A}}$-binder. However, the potential MBR violations can be circumvented if we assume an IP- 
adjoined trace of what, as in (28): ${ }^{9}$

(28) a. [what ${ }_{j}$ do [IP you wonder [CP whether [IP everyone ${ }_{i}$ [IP $\underline{x}_{j}$ [IP $x_{i}\left[v P \underline{x}_{j}\left[v P\right.\right.$ bought $\left.\left.\left.\left.\left.\left.\left.\left.x_{j}\right]\right]\right]\right]\right]\right]\right]\right]$

b. [CP what ${ }_{j}\left[\right.$ didn't [IP everyone ${ }_{i}\left[I P \underline{x}_{j}\left[I P x_{i}\left[v P \underline{x}_{j}[v P\right.\right.\right.$ buy $\mathrm{x}_{\mathrm{j}}$ ]]]]]]]

If the conclusion of the previous section is valid, we should expect there to be ambiguity in (28). According to $A \& L, \underline{\underline{x}}_{j}$ should not be deleted, since it is antecedent-governed by $\underline{x}_{\mathrm{j}}$ in the IP-adjoined position. But the latter trace should be deleted, due to the intervention of whether and the negation. If we follow A\&L's logic, (24a) and (25b) should be ambiguous, since in their LFs, what c-commands everyone and the latter c-commands $\underline{\underline{x}}_{j}$ in the VP-adjoined position. The fact that neither sentence is ambiguous makes A\&L's conclusion less convincing. A\&L might say that $\underline{x}_{j}$ would be deleted, which would make it impossible for $\underline{\underline{x}}_{j}$ to be properly governed, but it is not prima facie obvious under A\&L's approach what prevents $\underline{\underline{x}}_{j}$ from being properly governed before the deletion of $\underline{x}_{j}$.

The following sentences also pose serious problems for A\&L's approach to quantifier scope:

(29) a. What do you wonder whether Mary said everyone bought?

(what > everyone)

b. What didn't you think everyone bought?

(what > everyone)

The sentences in (29) have the following LF representations:

(30) a. [what ${ }_{j}$ do [you wonder [whether [Mary said [ $\underline{x}_{j}$ [everyone $_{i}\left[\mathrm{x}_{\mathrm{i}}\right.$ [vP $\underline{\underline{x}}_{\mathrm{j}}$ [vP bought $\left.\left.\left.\left.\left.\left.\left.\left.\mathrm{x}_{\mathrm{j}}\right]\right]\right]\right]\right]\right]\right]\right]$

b. $\left[w_{h a t}{ }_{j}\left[\right.\right.$ didn't you think $\left[\underline{x}_{j}\right.$ [everyone ${ }_{i}\left[x_{i}\left[v P \underline{x}_{j}[v P\right.\right.$ bought $\left.\left.\left.\left.\left.\left.\mathrm{x}_{\mathrm{j}}\right]\right]\right]\right]\right]\right]$ ]

9 In Chomsky (1986), wh-phrases are not allowed to adjoin to the defective IP category on their way to SPEC CP. If they were, the following sentence would not be accounted for:

(i ) ${ }^{*}\left[\mathrm{CP}\right.$ How do [IP you [ $\mathrm{VP}_{\mathrm{P}} \mathrm{t}_{3}\left[\mathrm{vP}\right.$ wonder [CP whether [IP $\mathrm{t}_{2}\left[\mathrm{John}\left[\mathrm{VP}_{\mathrm{V}} \mathrm{t}_{1}[\mathrm{vP}\right.\right.$ fixed the car $t]]]]]]]]]$

Tonoike and Oishi (1992) report that Chomsky (1991 MIT class lectures) defines the notion of barriers as (ii):

(ii) a. A lexical category L-marks its complement.

b. A non-L-marked category is a barrier.

c. adjunction to an argument is prohibited.

Barriers are all inherent, an assumption which makes it possible to adjoin to IP. 
In these representations, $\underline{\underline{x}}_{j}$ in the VP-adjoined position is properly governed by $\underline{x}_{j}$, allowing $\underline{\underline{x}}_{\mathrm{j}}$ to be present at LF. However, this predicts that since everyone $\mathrm{i}_{\mathrm{i}} \mathrm{c}$-commands $\underline{\underline{x}}_{\mathrm{j}}$, everyone can have scope over who, yet this is not the case.

A further look at cases not involving islands also reveals drawbacks with A\&L's approach. Consider the following examples from Sloan (1991):

(31) a. Who does everyone think you saw? (who >everyone)

b. Who do you think everyone saw? (who = everyone) According to A\&L, ambiguity should be manifest in both sentences since the QPs are in subject positions and the Wh-phrases move from object positions in (31), where no island-inducing factors are involved. Consider the following LFs of (31) with irrelevant adjunction of who omitted:

a. $\left[_{\mathrm{CP}} \mathrm{who}_{\mathrm{j}}\right.$ does [IP everyone ${ }_{\mathrm{i}}$ IIP $_{\mathrm{i}}$ think [IP you [VP $\underline{\underline{x}}_{\mathrm{j}}[\mathrm{VP}$ saw $\left.\left.\left.\left.\left.\left.\mathrm{x}_{\mathrm{j}}\right]\right]\right]\right]\right]\right]$

b. [CP who $_{j}$ do [IP you think [IP everyone ${ }_{i}$ IIP $_{\mathrm{x}_{\mathrm{i}}}\left[\mathrm{VP} \mathrm{x}_{\mathrm{j}}[\mathrm{VP}\right.$ saw $\left.\left.\left.\left.\left.\mathrm{x}_{\mathrm{j}}\right]\right]\right]\right]\right]$ ]

In both representations, who c-commands everyone with the latter ccommanding $\underline{\underline{x}}_{\mathrm{j}}$ in the VP-adjoined position, which wrongly predicts that the examples in (31) should both be ambiguous. It is easy to see here that the inverse scope of everyone is possible only when the Whphrase and the QP are clausemates at D-Structure.

In concluding this section I would like to emphasize the fact that A\&L's approach to scope relies in a critical way on intermediate traces, which have turned out to cause some problems for their analysis. The data which they cite and I cite in this section do not establish the conclusion that they draw.

\section{Subjacency and ECP in the Minimalist Framework}

In this section we will examine how island conditions are treated in the Minimalist framework. A key feature distinguishing the Minimalist framework from the Pre-Minimalist framework is the absence of the notion of government, which downgrades the ECP into "descriptive taxonomy." (The main motivation for the elimination of government from grammar is that the notion is not characterized by "virtual conceptual necessity.") Thus, A\&L's government-oriented approach does not fit well with the Minimalist Program. Chomsky (1993) and 
Chomsky and Lasnik (1993) derive the Subjacency and ECP effects from economy considerations.

Let us now turn to the following representations:

(33) a. [CP which car do [IP $t_{6}$ [IP you [VP $t_{5}$ [vP think [CP $t_{4}[\mathrm{C}$ that [IP $\mathrm{t}_{3}$ [IP John [vP $\mathrm{t}_{2}$ [vP fixed $\left.\left.\left.\left.\left.\left.\left.\left.\left.\left.\left.\mathrm{t}_{1}\right]\right]\right]\right]\right]\right]\right]\right]\right]\right]\right]$

b. ?[ ${ }_{\mathrm{CP}}$ which car do [ $\mathrm{vP}_{5} \mathrm{t}_{5}$ [IP you [ $\mathrm{vP}_{\mathrm{t}} \mathrm{t}_{4}$ [vP wonder [CP whether [IP $\mathrm{t}_{3}{ }^{*}$ [IP John [VP $\mathrm{t}_{2}$ [VP fixed $\mathrm{t}_{1}$ ]]]]]]]]]]

c. ${ }^{*}\left[\mathrm{CP}\right.$ How do [VP $\mathrm{t}_{5}$ [IP you [vP $\mathrm{t}_{4}[\mathrm{vP}$ wonder [CP whether [IP $\mathrm{t}_{3}{ }^{*}$ [IP John [VP $\mathrm{t}_{2}$ [vP fixed the car $\mathrm{t}_{1}$ ]]]]]]]]]]

Chomsky and Lasnik (1993: 546-547) claim that legitimate LF objects are uniform chains and operator-variable constructions. Roughly speaking, chains are uniform if and only if their members are all in positions of the same type. $\mathrm{A}^{\prime}$-movement of arguments creates nonuniform chains since the heads and the intermediate traces are in $\bar{A}$-positions but the tails are in A-positions. In order to form legitimate LF objects, all intermediate traces must be deleted, forming operatorvariable constructions. However, $\mathrm{A}^{\prime}$-movement of adjuncts results in uniform chains, due to the fact that the heads, all intermediate traces and the tails are in $\overline{\mathrm{A}}$-positions. When a chain is already uniform, no further operations are applicable to it since the derivation has converged. Deletion of intermediate traces is not permissible in uniform chains. With this background in mind, consider again the derivations in (33). (33a) is a case of $\mathrm{A}^{\prime}$-movement of an argument, forming a nonuniform chain. Deletion of intermediate traces will form an operator-variable construction (which car, $\left.t_{1}\right)$. (33b) and (33c) are cases of $\mathrm{A}^{\prime}$-movement of an argument and of an adjunct from the $W h$-island, respectively. Here the step from $t_{3}$ to $t_{4}$ violates (34) (Chomsky and Lasnik (1993: 546)) since it should have moved into the embedded SPEC CP position already filled with whether. Thus, the offending trace $t_{3}$ is marked with an asterisk *.

(34) Minimize chain links.

The difference between the "Subjacency violation" in (33b) and the "ECP violation" in (33c) comes from the formation of uniform chains just mentioned: in the former, deletion of intermediate traces including $t_{3}{ }^{*}$ is permitted and the operator-variable construction consisting of which car and $t_{1}$ is interpreted at LF; in the latter, the starred trace $t_{3}{ }^{*}$ still survives at $\mathrm{LF}$, producing a more severe violation.

Consider the examples in (22), which $A \& L$ explain in terms of intermediate traces: 
(22) a. ?What do you wonder whether everyone bought?

b. What do you think everyone bought?

$$
\text { (what }>\text { everyone) }
$$

$($ what $=$ everyone $)$

Mental computation, if the conjecture on uniform chains is on the right track, cannot "see" intermediate traces in the cases of $\mathrm{A}^{\prime}$ '-movement as in (22). ${ }^{10}$ I will propose below an informal analysis of the interaction of $W H / Q P$ in (22) without invoking intermediate traces by following the ideas of Chierchia (1991), Chomsky (1993) and Chomsky and Lasnik (1993).

\section{Weak Crossover and the Scope Interaction}

Consider the following examples:

(35) a. Who does every graduate student admire?

b. Who admires every graduate student?

(36) a. Chomsky. (individual reading, 35a/35b)

b. John admires Hale, Tom admires Chomsky ...

(pair-list reading, $35 \mathrm{a} /{ }^{*} 35 \mathrm{~b}$ )

c. His/Her adviser. (functional reading, $35 \mathrm{a} /{ }^{*} 35 \mathrm{~b}$ )

(35a) allows three kinds of answers as seen in (36): (36a) indicates a

10 An anonymous reviewer points out that intermediate traces are relevant to anaphor-binding (see Chomsky (1991: fn. 37)):

(i) Which pictures of himself $\mathrm{i}_{\mathrm{j} / \mathrm{j}}$ did $J o h n_{\mathrm{i}}$ think that $T o m_{\mathrm{j}}$ would see?

Under the copy theory of movement proposed in Chomsky (1993), the trace left behind is not "empty" but contains the same content of the moved element. Thus, the actual structure of (i) is (ii):

(ii) [which pictures of himself] John thought [[TR1 which pictures of himself] [that Tom would see [TR2 which pictures of himself]]]

In (ii), himself contained in TR1 can take John as its antecedent by LF-movement of the reflexive to thought. The same operation applies to the reflexive in TR2, allowing himself to be bound by Tom. Note here that this account is crucially dependent on the generalization that intermediate traces feed in the interpretation of the reflexive. The point here is not, of course, to present and defend a fullfledged theory of reconstruction problems, but rather to observe that the deletion of argument intermediate traces rests on the formation of uniform chains and the operator-variable construction. I assume here that only the operator feature is deleted in TR1, still leaving the reflexive intact there and making it possible for John to bind himself. See Ike-uchi (1993) for the problems inherent in reconstruction phenomena in the Minimalist framework. 
particular person that every student admires; (36b) is usually interpreted as the universal QP having a wide scope; his/her adviser in (36c) is a function from graduate students into their advisers. (35b), however, only allows the individual reading.

The pair-list reading is not available with downward entailing quantifiers, such as no and few, and quantifiers such as many and all the:

(37) a. Who does no Italian married man like?

b. His mother in law. (functional reading)

c. Giovanni, Maria; Paolo, Francesca ... (pair-list reading)

It can be seen from (36) and (37) that the functional reading is the prerequisite for the pair-list reading. It can also be seen from (38c) that the functional reading answer contains a bound variable (if we assume that (38b) is derived from (38c) for expository purposes):

(38) a. Who does every graduate student admire?

b. His or her adviser (functional reading)

c. Every graduate student admires his or her adviser.

Chierchia (1991) proposes that when the $W h$-phrase moves, it leaves a complex trace consisting of the $\mathrm{f}$ (unction)-index ( $j$ in (39)) and the a(rgument)-index ( $i$ in (39)). The former is bound by the $W H$ in CP and the latter corresponds to a bound pronominal.

(39) $\mathrm{WH}_{\mathrm{i}} \ldots \ldots \quad\left[\mathrm{NP} \mathrm{t}_{\mathrm{i}} \operatorname{pro}_{\mathrm{j}}\right]_{\mathrm{i}}$

With this idea in mind, consider (40a) and (40b), which correspond to (35a) and (35b), respectively:

(40) a. [who $\mathrm{i}_{\mathrm{i}}\left[\right.$ every graduate student $\left.\left.\mathrm{j}_{\mathrm{j}}\left[\operatorname{admires}\left[\mathrm{t}_{\mathrm{i}} \text { pro }_{\mathrm{j}}\right]_{\mathrm{i}}\right]\right]\right]$

b. $\left[w^{2} o_{i}\left[\left[t_{i} \text { pro }_{j}\right]_{i}\right.\right.$ admires [every graduate student $\left.\left.\left.t_{j}\right]\right]\right]$

The functional reading in (40b) induces a Weak Crossover (WCO) violation with respect to the configuration of every graduate student $t_{j}$ and pro $_{\mathrm{j}}$. To get a pair-list reading, Chierchia suggests that the quantifier generates a domain. The pair-list reading is as if it were a list which pairs members in a domain and members in a range. "To draw a list, we need a domain to draw members from. What determines such a domain in the case at hand? Quite clearly the quantifier that binds the a-index. From which quantifier meanings can we immediately retrieve a domain? From those that have a generator set, viz. the universal ones." (Chierchia (1991: 83)) Chierchia argues that the lack of the pair-list reading can be subsumed under the WCO violation.

This analysis extends to the following examples from Chierchia (1991), where the pair-list reading is available only in (41a): 


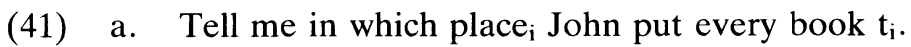

b. He put Formal Philosophy on his desk, $L G B$ on his night stand.

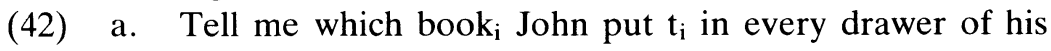
desk.

b. ${ }^{*} \mathrm{He}$ put Formal Philosophy on his desk, LGB on his night stand.

Chomsky and Lasnik (1993: 536) suggest that Wh-phrases such as who and whom are composed of a $w h$-feature, an indefinite quantifier, and the restriction on the quantifier. We regard 'an indefinite quantifier' here as 'an indefinite pronoun', following the idea put forth by Chomsky (1964), Kuroda (1965) and Nishigauchi (1990) that the Wh-phrases such as who and what contain indefinite pronouns. Under the Copy Theory of Movement (43), it follows that the trace of who/ what contains a wh-feature, an indefinite pronoun, and the restriction on the quantifier.

(43) The trace left behind is a copy of the moved element (Chomsky (1993: 35)).

The indefinite pronoun inside the $w h$-phrase trace can turn into a bound variable when there is an appropriate binder as in (40a), and it gives rise to scope interactions with other quantifiers.

We extend our analysis to the following sentences from $S S$ :

(44) a. Where ${ }_{i}$ did everyone hit him $t_{i}$ ?

b. When $n_{i}$ did everyone hit him $t_{i}$ ?

(45) a. Why did everyone hit him $t_{i}$ ?

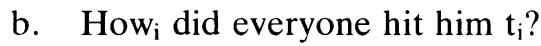

The pair-list reading is available only in (44). Huang (1982) notes that where and when, unlike why and how, can appear as a complement of a preposition, as in (46):

(46) a. to where / till when

b. *in how / * for why

Huang also points out that where and when have corresponding pronominal forms there and then, but that no pronominal counterparts can be found for why and how. Based on these observations, he concludes that where and when are NPs. We interpret this conclusion as indicating that traces of where and when, unlike those of why and how, contain indefinite pronouns. In (44), the indefinite pronoun inside the $w h$-phrase is bound by everyone, allowing the pair-list reading. However, wh-traces of how and why do not contain indefinite 
pronouns, since they are not NPs. Thus, they cannot induce the pairlist reading.

Consider also the following examples from $S S$ :

(47) a. Where $e_{i}$ did he hit everyone $t_{i}$ ?

b. When $n_{i}$ did he hit everyone $t_{i}$ ?

The pair-list reading is impossible here. This is to be expected if we assume that the $w h$-trace $t_{\mathrm{i}}$ is not c-commanded by everyone.

In this section I have incorporated Chierchia's ideas into the Minimalist Program and given a unified analysis of QP/Wh-adjunct interaction.

\section{Some Speculations on QR}

We have so far said nothing about the status of QR in the Minimalist framework. Kitahara (1992) and Yusa (1993) try to dispense with QR by the A-movement of QPs to SPEC AGRP for Case-checking. The intuitive idea behind these proposals is that in terms of Greed (i.e., operation is morphologically driven), the traditional QR is dubious. Before going into the discussion, let us look at the status of pied-piping at LF in the Minimalist Program. The relevant example is given in (48a), from Chomsky (1993: 25):

(48) a. *Who [t said he liked $\left[{ }_{\alpha}\right.$ how many pictures that John took]]

b. [[How many pictures that John took] who] [t said he liked $\left.\mathrm{t}^{\prime}\right]$

c. [[How many] who] [t said he liked [[ $\mathrm{t}^{\prime}$ pictures] that John took]]

In the Pre-Minimalist framework, (48a) shows that the Binding Theory applies at S-Structure. The adjunction of $\alpha$ to who results in the LF representation (48b), where he does not c-command John. This LF, however, runs counter to the claim in the Minimalist Program that the Binding Theory applies at LF. Chomsky (1993) rejects the LFmovement of pied-piped phrases ( $\alpha$ in (48a)) and instead proposes that only how many adjoins to who in (46c), an operation which he calls Absorption. In (48c), he c-commands John and cannot refer to John. The crucial idea here is that the operator position should be minimal. ${ }^{11}$

11 Chomsky (1993: 25) deals with wh-in-situ constructions, arriving at the con- 
In this section I will propose that $\mathrm{QR}$ does exist but it moves only $\mathrm{Q}$, the head of the QP, like LF Wh-movement. This explains the example in (1b), reproduced as (49):

(49) ${ }^{*}$ He liked every book that John read.

QR moves only every, so that he continues to c-command John at LF. Beghelli (1993) observes that the traditional QR adjoining a QP of any kind overgenerates scope ambiguities, and proposes to restrict the application of QR only to distributive universal quantifiers such as every $N{ }^{12}$ In Minimalist terms, every has a weak feature [+Dis(tributive)], since $\mathrm{QR}$ is a covert movement. It follows that $\mathrm{QR}$ involves feature-checking. For a concrete example, consider the following sentence:

(50) Two boys met every man. (two boy $=$ every man) In order to incorporate Beghelli's idea into Kitahara (1992), we assume, following Schmitt (1993), that after every man gets Case-

clusion that pied-piping is not legitimate for LF wh-movement. Hornstein (1994: fn. 12) observes that the prohibition on pied-piping at LF holds for QR as well.

(i) *Mary said that Peter bought every picture of herself.

(ii) Mary said that pictures of herself, Bill really likes.

If $\mathrm{QR}$ adjoined every picture of herself to IP, then we could not account for the difference between (i) and (ii). One way out is to assume that QR does not allow pied-piping, either.

12 Consider the following examples from Beghelli (1993):

(i) a. Every student passed fewer than six classes.

b. Each student passed a (possibly) different set of fewer than six classes.

c. *Each of fewer than six classes was passed by every student.

(ii) a. Fewer than six students passed every class.

b. Each individual in a set of less than six students passed every class.

c. Every class was passed by a (possibly) different set of less than six students.

(iii) a. Fewer than six students passed four classes.

b. ?Each individual in a set of less than six students passed (possibly) different set of less than six students.

The wide scope reading of the object varies with the type of QPs in the object positions: impossible in (ia); possible in (iia); possible but more likely than the wide scope of the subject in (iiia). Beghelli proposes that only distributive universals undergo QR. Bare numeral QPs, such as six men, many men take 'virtual scope' by local existential closure at VP or IP, or they are bound by the specificity operator in CP. Modified numeral QPs, such as fewer than six men and more than six men, are quantifiers but are immune to the application of QR or the existential closure, acquiring scope in situ. 
checked in SPEC AGRoP, every moves through [AGRo V] to T, which, I assume, has the feature [+Quantification] optionally. ${ }^{13}$ Then the amalgamated $\mathrm{T}$ moves to AGRs, resulting in the following representation:

(51) [AGRsP two boys [AGRs' every $\left._{j}+T_{i}+V\right]_{i}\left[T_{P} t_{i}\left[\right.\right.$ AGRoP $\left[D P t_{j}\right.$ $[\mathrm{NP} \operatorname{man}]]_{\mathrm{k}}\left[\right.$ AGRo $\left.\left.\left.\left.^{\prime} \mathrm{t}_{\mathrm{v}}\left[\mathrm{vP}_{\mathrm{v}} \mathrm{t}_{\mathrm{v}} \mathrm{t}_{\mathrm{k}}\right]\right]\right]\right]\right]$

If we assume that $\alpha$ takes scope over $\beta$ (i) if there is a $\operatorname{SPEC}(\beta)$ Head $(\alpha)$ agreement, or (ii) $\alpha$ c-commands $\beta$ if there is no SPECHead agreement. ${ }^{14}$ Thus, the wide scope reading of every is captured by the SPEC-Head agreement between two boys and every. In the system proposed here, $\mathrm{T}$ is the locus of the feature that checks off the feature [ +Dis] on quantifiers such as every. The intuitive idea behind this proposal is that scope is generally "clause-bounded". To check off its $\mathrm{N}$-features of $\mathrm{T}$ against the features of the NP in SPEC AGRsP, the amalgamated $\mathrm{T}$ moves to AGRs.

Consider next the simplified structure which typically represents the pair-list reading, where the universal QP appears in the subject position and the Wh-phrase moves from the object position (see (8a)):

(52) $\left[\mathrm{CP}\right.$ what $_{\mathrm{k}}\left[\mathrm{C}^{\prime}\right.$ every $\left.\mathrm{i}+\mathrm{V}\right]\left[\mathrm{AGRsP}\left[\mathrm{DP} \mathrm{t}_{\mathrm{i}} \mathrm{NP}\right]_{\mathrm{j}}\left[\mathrm{AGRs}^{\prime} \ldots\left[\begin{array}{ll}\mathrm{TP} & \ldots\end{array}\right.\right.\right.$ $\left.\left.\left.\left.\left[\mathrm{vP}_{\mathrm{v}} \mathrm{t}_{\mathrm{v}}\left[\mathrm{t}_{\mathrm{k}} \operatorname{pro}_{\mathrm{j}}\right]_{\mathrm{k}}\right]\right]\right]\right]\right]$

Schmitt assumes that the DP containing every first moves to SPEC AGRsP to check its Case feature and the strong nominal features of $\mathrm{T}$, and from there every further moves to $\mathrm{C}$ to incorporate into the $[\mathrm{V}+\mathrm{C}]$ complex. In this structure, no WCO violation is observed and the SPEC-Head agreement in CP permits every to have wide scope.

However, this approach makes a wrong prediction in cases like (31), reproduced as (53):

(53) $W_{h o}$ does everyone think you saw $t_{i}$ ? (who $>$ everyone) This sentence takes on an LF structure similar to (52) in relevant respects. One way out is to suppose that an indefinite pronoun in the trace of a $w h$-phrase is subject to the Binding Condition A, so that the pronoun is not bound locally by every in (53). ${ }^{15}$ Another is to assume

13 Or it may be possible to postulate Quantifier Phrase between TP and VP, possibly under the NegP, if we consider the following example:

(i) John did not read every paper on QR. (not>every paper)

14 I diverge here from the following scope rule proposed in Schmitt (1993):

(i) $\alpha$ is in the scope of $\beta$ if $\alpha$ is in the projection of $\beta$.

15 Sloan (1991) assumes that $W h$-movement leaves a trace containing an anaphor 
that every does not have to move into $C$ with some stipulations on $\mathrm{QR}$, more generally, LF-movement. QR does not have PF effects, so it is not clear whether every moves or [ + Dis] moves. If every moves at $\mathrm{LF}$, it functions like a clitic and finally head-moves to $\mathrm{T}$ to check the feature [+Dis]. Schmitt (1993) attributes to the head-movement the fact that QR does not license parasitic gaps, since the movement does not license parasitic gaps. On the other hand, if the feature [+Dis] moves at LF, it does not seem reasonable to refer to X-bar distinctions such as X/X'/XP. Recently, Fox (1994) extends economy considerations to semantics to explain VP-ellipsis, and suggests that $\mathrm{QR}$ applies only if it yields some semantic consequences or different interpretations. $^{16}$ If this is tenable, the application of QR is more restricted than has been proposed. In (53) there might be no movement of every via QR. It might be the case that movement of every occurs only when it is checked against the $\mathrm{T}$ in the clause containing the other interacting quantifier or the trace of the Wh-phrase. In the Minimalist framework, Procrastination dictates that movement take place as late as possible, so that LF movement is preferable to overt movement. ${ }^{17}$ However, QR is costly in that movement affects semantics, unlike the movement of DP to AGRP for Case-checking. The latter movement has no effect on semantic interpretation. The movement of the object $\mathrm{Q}$ is motivated, since the object $\mathrm{Q}$ taking scope over the subject $\mathrm{Q}$ cannot be captured in terms of the linear order. However, this is not the case with the subject Q. Further research is necessary to clarify the exact nature of the subject $Q$ raising.

It should now be clear that in order to get the pair-list reading, the quantifier is required to be marked with the feature [ $+\mathrm{Dis}]$, in addition to the absence of a WCO violation. We will consider here the feature [+Dis] in Japanese. It is not unreasonable to assume that sorezore 'each,' unlike subete 'every/all,' has the feature [+Dis]. If this is valid, the following contrast can be expected on the assumption that

subject to the Binding Condition A. This is illustrated in the following ambiguous sentence from Sloan (1991):

(i) Who do you think everyone saw?

16 Some extension has to be made of the notion Greed.

17 In the Minimalist framework, LF movement is in a sense "unmarked," in contrast to the idea that overt movement is unmarked in the Pre-Minimalist framework. 
QR applies to sorezore, but not to subete. ${ }^{18}$
(54)
a. Dono hon-o
sorezore-no gakusei-ga
which book-Acc each-Gen student-Nom
yomimashita-ka
read-Q
'Which book did each student read?'
b. John-wa $L G B$-o, Bill-wa $S S$-o, $\ldots$
John-Top LGB-Acc, Bill-Top SS-Acc
'John read $L G B$, Bill read $S S, \ldots$ '
(55)
a. Dono hon-o subete-no gakusei-ga
which book-Acc every-Gen student-Nom yomimashita-ka
read-Q
'Which book did every student read?'
b. *John-wa LGB-o, Bill-wa $S S$-o, ...
John-Top LGB-Acc, Bill-Top SS-Acc
'John read $L G B$, Bill read $S S, \ldots$ '

In (54), sorezore moves into $\mathrm{C}$, inducing a SPEC-Head agreement with dono hon in SPEC CP. This allows (54a) to have a pair-list reading. However, no QR applies to subete in (55), resulting in the lack of the pair-list reading.

Let us turn to problems which have been left unanswered:

a. ?What do you wonder whether everyone bought?

b. What didn't you think everyone bought?

$$
(=(22 a) \text { (what }>\text { everyone })
$$

$$
(=(29 b)) \text { (what }>\text { everyone })
$$

We have seen that every has a [+Dis] feature, but given the fact that it functions as an operator, we assume that it contains the operator feature as well. Considering $(57 a-b)$, it seems that every with the feature $[+\mathrm{OP}]$ cannot cross another operator on the way to what:

(57) a. what $[+$ Wh OP $] \ldots$ whether $[+$ Wh OP $] \ldots$ every $[+$ Dis OP $] \ldots$

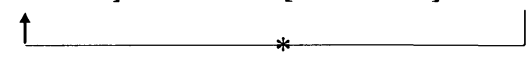

(58) a. what $[+$ Wh OP $] \ldots$ n't $[+$ Neg OP $] \ldots$ every $[+$ Dis OP $] \ldots$

18 Schmitt (1993) assumes that todo, a universal Q in Brazilian Portuguese, is a modifier adjoined to DP and does not move to CP. So it might be the case that subete, though specified as [+Dis], does not raise, like todo. 
If this observation is correct, every in (56) cannot cross whether or Neg, so that it acquires narrow scope. This is a kind of minimality effect in terms of features, but it does not refer to positions such as $\mathrm{A} / \overline{\mathrm{A}}$, or bar levels such as $\mathrm{X} / \mathrm{X}^{\prime} / \mathrm{XP}$. On a very speculative note, the cases in (57) and (58) may follow from the generalized form (59): ${ }^{19}$

(59) In a configuration such that $\ldots \mathrm{X}[+\alpha] \ldots \mathrm{Y}[+\beta] \ldots \mathrm{Z}[+$ $\gamma$ ], where $\mathrm{X}$ c-commands $\mathrm{Y}$ and $\mathrm{Y}$ c-commands $\mathrm{Z}$, and $\alpha$, $\beta$ and $\gamma$ are operator features, $Z$ cannot cross $Y$ on the way to $X$ to get its operator feature checked. Otherwise it would result in a "Minimal Link Condition" violation.

Consider the following contrast:

(60) a. *? Who said that Egbert drew every picture of who?

(Diesing (1992))

b. Who said that Egbert drew many pictures of who?

Wh-Absorption is not possible in (60a), where every is involved. We can account for this contrast by assuming (i) that many does not have the relevant OP feature, so it is immune to (59) or (ii) that every and many, both marked as [+OP], are in different positions as in (61):

(61) a. [DP every [NP picture of who]]

b. [DP [NP many pictures of who]]

In (61), every in D marks the whole DP with [ $+\mathrm{OP}]$, which acts as an intervening element between the two whos in (60a).

The intervention effect of every can be seen in the licensing of a negative polarity item (NPI) like any:

(62) a. *John never read every book that had any pages missing.

(Bowers (1987))

b. John never read many books that had any pages missing.

(63) a. *I don't know that everyone read anything.

b. I don't know that many people read anything.

In (62a) and (63a), the operator feature [ + Neg OP] on any cannot be properly checked against the $[+\mathrm{Neg} \mathrm{OP}]$ on never or $n$ 't because of the intervening operator feature [ $+\mathrm{Dis} \mathrm{OP}]$ on every.

The interesting contrast can be seen in (64):

(64) a. I don't know what everybody read. (what = everybody)

b. I don't know what anybody read. (anybody $>$ what)

19 See Kitahara (1994) for the argument that a variety of movement effects can be captured by the economy condition called RESTRICT. 
According to the Copy Theory of Movement, (64b) has the following structure, with irrelevant details omitted:

(65) I don't know what anybody $_{\mathrm{j}}$ read $\left[\mathrm{t}_{\mathrm{i}} \text { pro }_{\mathrm{j}}\right]_{\mathrm{i}}$

In (65), the intervening what blocks the movement of any to NEG, so I assume that LF computation uses the lower copy of the wh-trace for interpretation. This is seen roughly as in (66):

(66) I don't know anybody ${ }_{j}$ read [wh pro ${ }_{j}$ ]

The only scope we get in (66) is that anybody has scope over what. In (64a), however, no NPI is involved, so that ambiguity is induced.

The NPI also affects the ambiguity of negative scope:

(67) a. He didn't move because he was punished.

(Linebarger (1987))

b. His moving wasn't caused by his being punished.

c. His not moving was caused by his being punished.

(68) a. He didn't budge an inch because he was punished.

b. It was because he was punished that he didn't budge an inch.

If we assume that in order for because to be in the scope of negation, the optional feature [ $+\mathrm{Neg}$ ] assigned to because moves to NEG in the matrix clause at LF. When the $[+\mathrm{Neg}]$ feature exists in a becauseclause, it moves to NEG and yields the interpretation in (67b). When the $[+\mathrm{Neg}]$ is not present in the subordinate clause, it does not move, giving rise to the reading as shown in (67c), where the because-clause is not affected by negation. However, in (68a) the because-clause cannot possess the $[+\mathrm{Neg}]$. Otherwise, it would cross the [+Neg] on budge an inch on its way to the $[+\mathrm{Neg}]$ on $n^{\prime} t$ in the matrix clause, resulting in the violation of (59). As a result, the because-clause does not have the $[+\mathrm{Neg}]$ and is outside the scope of negation, as indicated in $(68 \mathrm{~b})$.

\section{Concluding Remarks}

The postulation of LF has been justified on the grounds that it can explain grammatical generalizations that could not be captured without reference to this level. Within the Pre-Minimalist versions of the Principles and Parameters approach as well, LF is the interface level between grammar and the conceptual-intensional system, but $\mathrm{D}$ structure and S-Structure conditions and principles, which are discarded or subsumed under LF principles in the Minimalist Program, are also assumed to be responsible for wellformedness. Scope ambiguities are 
represented at LF by applying LF-movements, QR being among them, to S-Structure. The ECP-oriented approach to scope cannot be incorporated into the Minimalist Program, because ECP is a "descriptive taxonomy" of no theoretical importance.

I have reviewed and discussed the analyses proposed in $S S$, pointing out some problems and revisions in terms of the Minimalist Program. We have seen that arguments which motivate the modifications of A\&L's analyses of scope phenomena do not establish their claims: two major problems in $S S$ are the discrepancy in the function of c-command with respect to the MBR and the SP in the final version of their proposal, and the treatment of intermediate traces. I have proposed, essentially following the ideas put forth by Chierchia (1991) and Schmitt (1993), that QR does exist, but that it raises only Q or its operator feature. I have also extended the LF-Q movement analysis to the interactions between negation and quantified expressions. SS relies heavily on conditions and principles which have been reduced to interface conditions in the Minimalist Program, but the book should not be criticized for this reason since it was written before the advent of the Minimalist Program. Rather, A\&L are to be praised for taking on the task of developing the most comprehensive theory of scope phenomena in the Pre-Minimalist Program. Finally, it is interesting to note that the MBR advocated by $A \& L$ is very close in spirit to the Minimal Chain Link as both conditions refer to the nearest relevant category.

\section{REFERENCES}

Aoun, Joseph and Yen-hui Audrey Li (1989) "Constituency and Scope," Linguistic Inquiry 20, 141-172.

Aoun, Joseph and Yen-hui Audrey Li (1991) "The Interactions of Operators," Principles and Parameters in Comparative Grammar, ed. by Robert Freidin, 163-181, MIT Press, Cambridge, MA.

Beghelli, Filippo (1993) "A Minimalist Approach to Quantifier Scope," NELS 23, ed. by Amy J. Schafer, 65-79.

Bowers, John (1987) "Extended X-Bar Theory, the ECP and the Left Branch Condition," WCCFL 6, ed. by Megan Crowhurst, 47-62.

Chomsky, Noam (1964) The Current Issues in Linguistic Theory, Mouton, The Hague.

Chomsky, Noam (1981) Lectures on Government and Binding, Foris, Dor- 
drecht.

Chomsky, Noam (1986) Barriers, MIT Press, Cambridge, MA.

Chomsky, Noam (1991) "Some Notes on Economy of Derivation and Representation," Principles and Parameters in Comparative Grammar, ed. by Robert Freidin, 417-454, MIT Press, Cambridge, MA.

Chomsky, Noam (1993) "A Minimalist Program in Linguistic Theory," The View from Building 20: Essays in Linguistics in Honor of Sylvain Bromberger, ed. by Kenneth Hale and Samuel Jay Keyser, 1-52, MIT Press, Cambridge, MA.

Chomsky, Noam (1994) Bare Phrase Structure, MIT Occasional Papers in Linguistics 5, MIT.

Chomsky, Noam and Howard Lasnik (1993) "The Theory of Principles and Parameters," Syntax: An International Handbook of Contemporary Research, ed. by Joachim Jacobs, Arnim von Stechow, Wolfgang Sternefeld and Theo Vennemann, 506-569, Walter de Gruyter, Berlin.

Chierchia, Gennaro (1991) "Functional WH and Weak Crossover," WCCFL 10, ed. by Dawn Bates, 75-90.

Diesing, Molly (1992) Indefinites, MIT Press, Cambridge, MA.

Fox, Danny (1994) "Quantifier Scope in VP Ellipsis," ms., MIT.

Hornstein, Norbert (1994) "An Argument for Minimalism: the Case of Antecedent Contained Deletion," Linguistic Inquiry 25, 455-480.

Hornstein, Norbert (1995) LF: The Grammar of Logical Form: From GB to Minimalism, Blackwell, Oxford.

Huang. C.-T. James (1982) Logical Relations in Chinese and the Theory of Grammar, Doctoral dissertation, MIT.

Huang. C.-T. James (1993) "Reconstruction and the Structure of VP: Some Theoretical Consequences," Linguistic Inquiry 24, 103-138.

Ike-uchi, Masayuki (1993) "Saikouchiku-Genshou ni Tuite (On Reconstruction Phenomena)," Eigo Seinen 139. 2, 75-77.

Kitahara, Hisatsugu (1992) "Checking Theory and Scope Interpretation without Quantifier Raising," Harvard Working Papers in Linguistics 1, ed. by Susumu Kuno and Höskuldur Thráinsson, 51-71, Harvard University.

Kitahara, Hisatsugu (1994) "Restricting Ambiguous Rule-Application: A Unified Analysis of Movement," MIT Working Papers in Linguistics 24: Formal Approaches to Japanese Linguistics 1, ed. by Masatoshi Koizumi and Hiroyuki Ura, 179-20, MIT.

Kuroda, Shige-Yuki (1965) Generative Grammatical Studies in the Japanese Language, Doctoral dissertation, MIT.

Lasnik, Howard and Mamoru Saito (1984) "On the Nature of Proper Government," Linguistic Inquiry 15, 235-289.

Linebarger C. Marcia (1987) "Negative Polarity and Grammatical Representation," Linguistics and Philosophy 10, 325-387.

May, Robert (1977) The Grammar of Quantification, Doctoral dissertation, MIT. 
May, Robert (1985) Logical Form: Its Structure and Derivation, MIT Press, Cambridge, MA.

Nishigauchi, Taisuke (1990) Quantification in the Theory of Grammar, Kluwer, Dordrecht.

Schmitt, Cristina (1993) "On the Necessity of QR as a Syntactic Rule," ms., University of Maryland.

Sloan, Kelly (1991) "Quantifier-Wh Interaction," MIT Working Papers in Linguistics 15, ed. by Lisa Cheng and H. Demirdash, 219-237.

Tonoike, Shigeo and Masayuki Oishi (1992) "Saishin Chomsky-Riron no Gaiyou (An Overview of the Latest Progress in Chomsky's Theory)," Eigo Seinen 138.8, 44-46; 138.9, 23-26.

Yusa, Noriaki (1993) "Kakushogou ni Tsuite (On CASE-Checking)," Eigo Seinen 139.3, 128-130.

Department of English

Miyagi Gakuin Women's College

Sakuragaoka, Aoba-ku

Sendai-shi

Miyagi 981

e-mail: i22535@cctu.cc.tohoku.ac.jp/yusa@mgu.ac.jp 